\title{
Impacts of Future Urban Expansion on Regional Climate in the Northeast Megalopolis, USA
}

\author{
Yingzhi Lin, ${ }^{1}$ Anping Liu, ${ }^{1}$ Enjun Ma, ${ }^{1}$ Xing Li, ${ }^{1}$ and Qingling Shi ${ }^{2,3}$ \\ ${ }^{1}$ School of Mathematics and Physics, China University of Geosciences (Wuhan), Wuhan 430074, China \\ ${ }^{2}$ Institute of Geographic Science and Natural Resource Research, Chinese Academy of Sciences, Beijing 100101, China \\ ${ }^{3}$ Center for Chinese Agricultural Policy, Chinese Academy of Sciences, Beijing 100101, China \\ Correspondence should be addressed to Yingzhi Lin; linyz.ccap@igsnrr.ac.cn
}

Received 21 June 2013; Accepted 14 August 2013

Academic Editor: Xiangzheng Deng

Copyright (C) 2013 Yingzhi Lin et al. This is an open access article distributed under the Creative Commons Attribution License, which permits unrestricted use, distribution, and reproduction in any medium, provided the original work is properly cited.

\begin{abstract}
In this paper, evidences for influences of future urban expansion on regional climate in the Northeast megalopolis, USA, are presented. The model-based analysis shows that future urban expansion will significantly result in regional climate change. An average annual temperature increase ranging from $2^{\circ} \mathrm{C}$ to $5^{\circ} \mathrm{C}$ in new urban area and an average annual temperature decrease ranging from $0.40^{\circ} \mathrm{C}$ to $1.20^{\circ} \mathrm{C}$ in the south of the megalopolis will be caused by future urban expansion. The average annual precipitation of the simulation area will decrease due to future urban expansion by $5.75 \mathrm{~mm}, 7.10 \mathrm{~mm}$, and $8.35 \mathrm{~mm}$ in the periods of 2010-2020, 2040-2050, and 2090-2100, respectively. The warming effect of future urban expansion in original and new urban area and drought effects in nonurban area will be more serious in summer than in winter. A cooling effect will turn up in original urban area in winter. This research further shows that a study at the scale of megalopolis helps to understand the integrated effect of combination and interaction of multiple cities and their surrounding areas which may crucially determine regional climate pattern and should be highly valued in the future.
\end{abstract}

\section{Introduction}

Urban expansion is regarded as one of the most noticeable effects of human activities that cover a very small fraction of Earth's land surface but notably affect climate. It usually removes and replaces crops and natural vegetation with nonevaporating and nontranspiring surfaces such as metal, asphalt, and concrete $[1,2]$. These artificial surfaces are characterized by specific thermal properties (albedo, thermal conductivity, and emissivity) which are different from those of nonurban areas [3-5]. The alteration of regional thermal properties along with urban expansion will inevitably result in the redistribution of incoming solar radiation and affect the surface energy budgets $[6,7]$. Consequently, the wind velocity, mixing layer depth, and thermal structures in the boundary layer, as well as the local and regional atmospheric circulations, are changed [8-11].

One of the most widely concerned phenomena of urban-induced climate change is the effect of urban heat island (UHI), which describes the difference in ambient air temperature between an urban area and its surrounding rural area. A lot of researches have been implemented focusing on the UHI in a single city [12-14]. Though neglecting the integrated effect of combination and interaction of multiple cities at regional scale, these researches help greatly in understanding the influences of urban expansion on climate. Back in the late 1960s, Bornstein pointed out urban surface temperature inversions to be less intense and far less frequent than those in the surrounding nonurban regions [15]. Afterwards, large quantities of empirical researches have proved that urban expansion can inevitably cause local temperature change. For example, the research of Kalnay and Cai suggested that half of the observed decrease in diurnal temperature range is due to land use changes especially urban expansion [16]. And according to the estimation of Rosenzweig et al. using global climate models (GCMs), the average difference in urban and nonurban minimum temperatures is $3.0^{\circ} \mathrm{C}$ for the Newark area and $1.5^{\circ} \mathrm{C}$ for Camden [17]. The statistical analysis of Yuan and Bauer using remote sensing data of Minnesota indicated there is a strong linear relationship between land 
surface temperature and percent impervious surface for all seasons [18]. Gaffin et al., analyzed the historical annual data of New York and found that the UHI intensification increase along with urban expansion is responsible for $1 / 3$ of the total warming that the city had experienced since 1900 [19]. Imhoff et al. found that urban expansion is the primary driver for the increase in temperature, explaining $70 \%$ of the total variance inland surface temperature in Los Angeles [20]. Kleerekoper et al. showed that the severe temperature rise in urban environments is caused by heat stresses aggravation of phenomenon UHI along with urban expansion [21]. Tian et al. found that the diurnal temperature ranges have tight correlation with urban areas in their study of Shenzhen, China [22]. Besides strengthening UHI effect, it has been found that urban expansion can significantly lead to local precipitation change. For instance, the study of Marshall Shepherd et al. illustrated the positive effects of urban areas on precipitation enhancement in the westnorthwest Houston area and suggested that the future urban expansion may lead to temporal and spatial precipitation variability in coastal urban microclimates [23]. And Guo et al. showed that the total accumulated precipitation in Beijing decreases especially in the urbanized region, and its distribution tends to become more concentrated and intensified along the borderline between urban and nonurban regions [24]. All above researches indicate that it is unambiguous that the urban expansion can result in local climate change.

In addition to researches of small scale and single city, there are evidences suggesting that the impacts of urban expansion on climate change are significant at a regional scale. Lin et al. found that the urban expansion over Taiwan's western plain perturbs thermal and dynamic processes and hence affects the location of thunderstorms and precipitation over western plain [25]. Trusilova et al. pointed out that the urban area in Europe results in an increase of urban precipitation in winter $(0.09 \pm 0.16 \mathrm{~mm} /$ day $)$ and a precipitation reduction in summer $(-0.05 \pm 0.22 \mathrm{~mm} /$ day $)$ [26]. Jacobson and Ten Hoeve pointed out that urban area is modeled over 20 years to increase gross global warming by $0.06-0.11 \mathrm{~K}$ and the UHI effect may contribute to $2 \%-4 \%$ of gross global warming [27]. And the researches of Sang et al. showed that the urban expansion in the Yangtze River Delta, China, causes obvious fluctuations of regional rain intensity and more uncertainty of daily precipitation variability [28]. These researches have sufficiently and undisputedly demonstrated that urban expansion affects local and regional climate changes. But for mega cities whose urban areas are still expanding such as New York, Beijing, Seoul, Chicago, and Moscow, there are still no sufficient evidences for the relationship between future urban expansion and regional climate at the scale of megalopolis. And arguments on the effects of urban expansion on large scale climate still exist [13]. In this paper, we present some evidences for effects of future urban expansion on regional climate based on the simulation of precipitation and temperature in the Northeast megalopolis of the United States of America (USA).

The primary objective of this study is to determine the influences of future urban expansion on regional climate on different time scales in developed megalopolis. The major contribution of this paper is that it provides evidences for influences of future urban expansion on regional climate at the scale of megalopolis and helps to understand the integrated effect of combination and interaction of multiple cities and their surrounding areas. The simulation results show that future urban expansion will lead to significantly climate change. One of the surprising findings is that there will be a cooling effect in original urban area in winter caused by urban expansion. The future urban expansion will result in an average annual temperature increase ranging from $2^{\circ} \mathrm{C}$ to $5^{\circ} \mathrm{C}$ in new urban area and an average annual temperature decrease ranging from $0.40^{\circ} \mathrm{C}$ to $1.20^{\circ} \mathrm{C}$ in the south of the megalopolis. The average annual precipitation will decrease by $5.75 \mathrm{~mm}, 7.10 \mathrm{~mm}$, and $8.35 \mathrm{~mm}$ in the periods of $2010-$ 2020, 2040-2050, and 2090-2100 due to future urban expansion, respectively. And the magnitude of warming effects and drought effects of future urban expansion will vary with the seasons. Our simulation scheme is described in Section 2. The atmospheric forcing dataset and the predicted urban expansion dataset used in our simulation are also introduced in this section. The results and discussions are provided in Section 3 and concluded in the final section.

\section{Data and Methodology}

2.1. Study Area. The Northeast megalopolis is the most populous and largely developed megalopolis of USA. It is constituted by a number of cities including Baltimore, Boston, Harrisburg, Newark, New York City, Philadelphia, Portland, Providence, Richmond, Springfield, Hartford, and Washington [29]. The megalopolis's population is expected to rise to sixty million by 2025 . This megalopolis is chosen as case study area because it is one of the most typical megalopolis globally which can be regarded as the example of future megalopolis development.

2.2. Simulation Scheme. The Weather Research and Forecasting (WRF-ARW) model based on the Eulerian mass solver was used in this study to investigate the temperature and precipitation changes driven by future urban expansion in the study area. This mesoscale model is a state-of-the-art atmospheric simulation system based on the Fifth-Generation Penn State/NCAR Mesoscale Model (MM5) [30]. Simulation from 2010 to 2100 with a constant underlying surface (the pattern of urban area as well as other land use and cover types in the study area is fixed to that of 1993, namely, baseline underlying surface) was implemented first, whose results are regarded as baseline. The effects of future urban expansion on climate can be measured by the difference of the simulation results with predicted underlying surface and baseline underlying surface (Figure 1):

$$
E_{i}=R_{i}-r_{i}
$$

where $i$ refers to average annual and monthly temperatures and average annual and monthly precipitations, $E$ is the effects of future urban expansion on climate, and $R$ and $r$ are the simulation results of WRF-ARW model with predicted underlying surface and baseline underlying surface, respectively. 


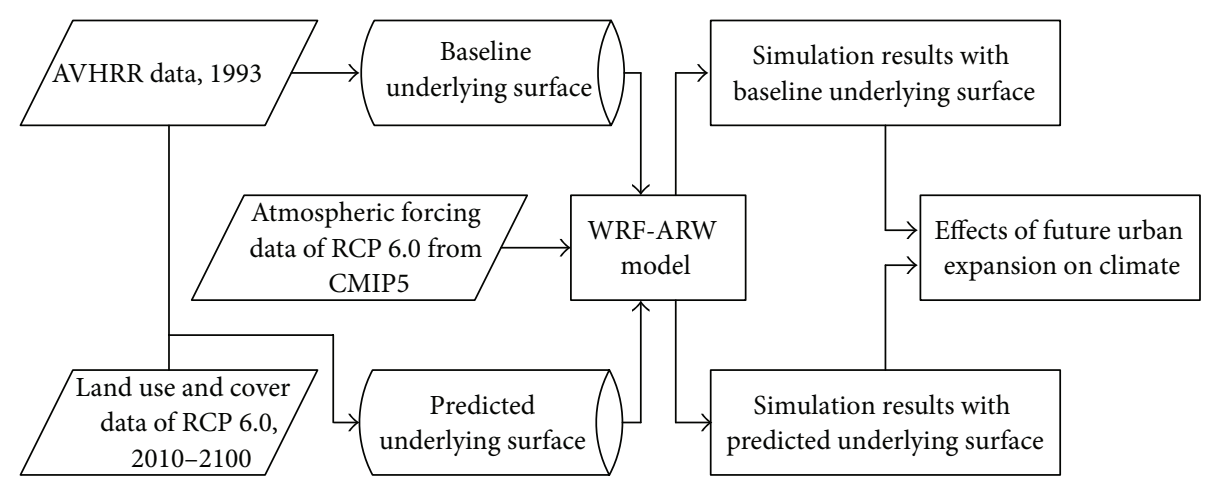

FIGURE 1: Simulation scheme and data processing framework.

2.3. Data and Process. An advanced very high resolution radiometer (AVHRR) grid data of $1 \mathrm{~km} \times 1 \mathrm{~km}$ of the United States Geological Survey's (USGS) classification system spanning a 12-month period (April 1992-March 1993, henceforth, 1993) was used as the baseline underlying surface data in this study (Figure 1). And the predicted land use and cover grid data of $0.5^{\circ} \times 0.5^{\circ}$ from 2010 to 2100 are derived from the database of Representative Concentration Pathway (RCP) 6.0. This database is developed by the Asia-Pacific Integrated Model (AIM) modeling team at the National Institute for Environmental Studies (NIES), Japan. The reason that we choose RCP 6.0 is because it is a stabilization scenario where total radiative forcing is stabilized after 2100 without overshoot by employment of a range of technologies and strategies for reducing greenhouse gas emissions [31, 32]. To investigate the effects of future urban expansion on climate, we only used the urban expansion information of the database, though change information of all kinds of land use and cover are available. Supposing other types of land use and cover constant, the new urban area pixels derived from the database of RCP 6.0 were overlaid to the map of baseline underlying surface. Consequently, two major underlying surface data, baseline underlying surface data directly derived from AVHRR data of 1993 and predicted underlying surface data by overlaying the urban expansion information to the map of baseline underlying surface, were finally obtained (Figure 1). And both of these two underlying surface data were transformed to grid data of $50 \mathrm{~km} \times 50 \mathrm{~km}$ by resampling (Figure 2). According to the data of RCP 6.0, urban area in the Northeast megalopolis had expanded rapidly during the period 1993-2010 and will continue to expand in the period 2010-2100.

The fifth phase of the Coupled Model Intercomparison Project (CMIP5) produces a state-of-the-art multimodel dataset designed to advance our knowledge of climate variability and climate change. The model output which is being analyzed by researchers worldwide underlies the Fifth Assessment Report by the Intergovernmental Panel on Climate Change $[33,34]$. It provides projections of future climate change on two time scales, near term (out to about 2035) and long term (out to 2100 and beyond). Model output of the latter of RCP 6.0 such as air temperature, specific humidity, sea level pressure, eastward wind, northward wind, and geopotential height from 2010 to 2100 was used as the atmospheric forcing dataset of WRF-ARW model (Figure 1).

\section{Results and Discussion}

The average effects of urban expansion on temperature and precipitation for each period of 2010-2020, 2040-2050, and 2090-2100 were calculated. In the simulation of three periods, the baseline underlying surface data and predicted underlying surface data were used. Concretely, the temperature and precipitation of each period of 2010-2020, 20402050, and 2090-2100 with baseline underlying surface were obtained first. And then the simulation of temperature and precipitation of three periods of 2010-2020, 2040-2050, and 2090-2100, was continuously implemented by using the predicted underlying surface of 2010, 2040, and 2090, respectively. As described above, the effects of future urban expansion on climate were measured by the difference of the simulation results with baseline and predicted underlying surfaces, which can also reduce the simulation bias induced by discontinuous simulation. The original simulation results were hourly and aggregated into average annual data and average monthly data.

3.1. Average Annual Temperature Effects. Figure 3 depicts the simulated effects of future urban expansion on average annual temperature in the Northeast megalopolis, USA. From the variation in average annual temperature change, it is shown that temperature will be locally and regionally affected by future urban expansion (Figure 3). The largest change in average annual temperature will occur in the new urban area (expanded urban area during 1993-2100), which can be certainly referred to UHI effects. The strongest UHI will lead to an increase of $5.73^{\circ} \mathrm{C}$ in average annual temperature in some new urban areas. And for most new urban areas, the average annual temperature will increase by $2^{\circ} \mathrm{C}$ to $5^{\circ} \mathrm{C}$ due to urban expansion from 1993 to the period of 2090-2100. The effects of future urban expansion on average annual temperature will be strengthened along with urban area increase. For instance, conversion from deciduous broadleaf forest to urban area will lead to the average annual temperature of the pixel $\left(39^{\circ} 59^{\prime} \mathrm{N}\right.$, $75^{\circ} 50^{\prime} \mathrm{W}$ ) rising by $3.15^{\circ} \mathrm{C}, 3.53^{\circ} \mathrm{C}$, and $3.76^{\circ} \mathrm{C}$ in the period of 2010-2020, 2040-2050, and 2090-2100, respectively. 


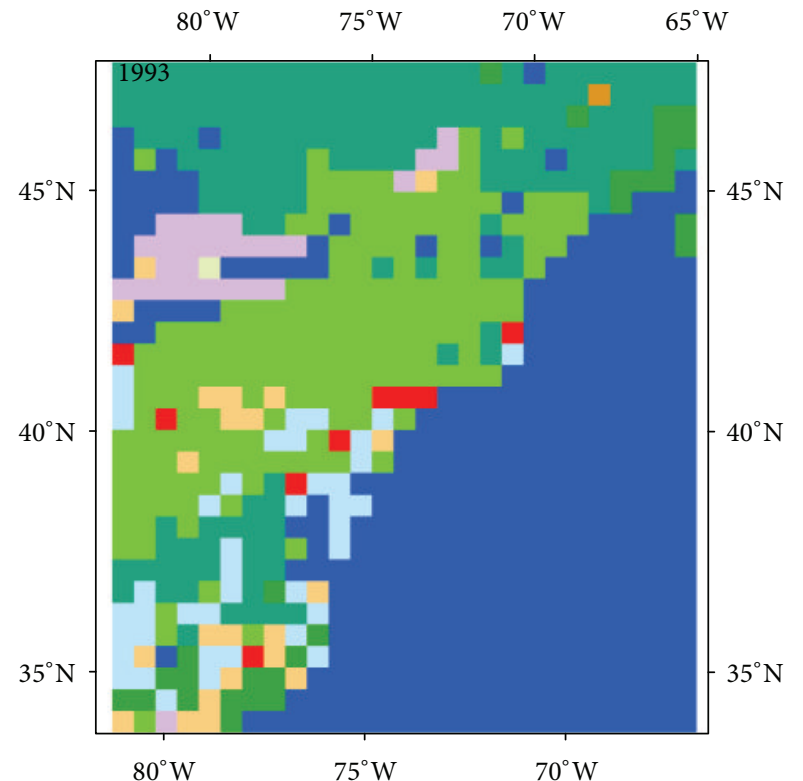

(a)

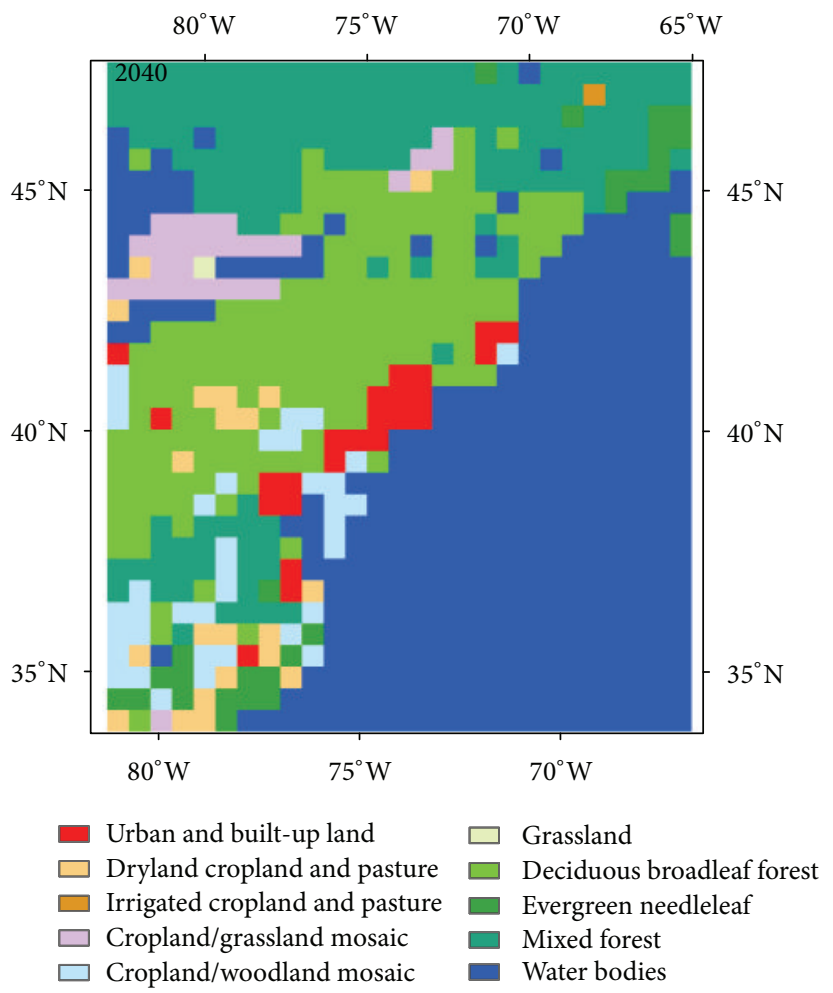

(c)

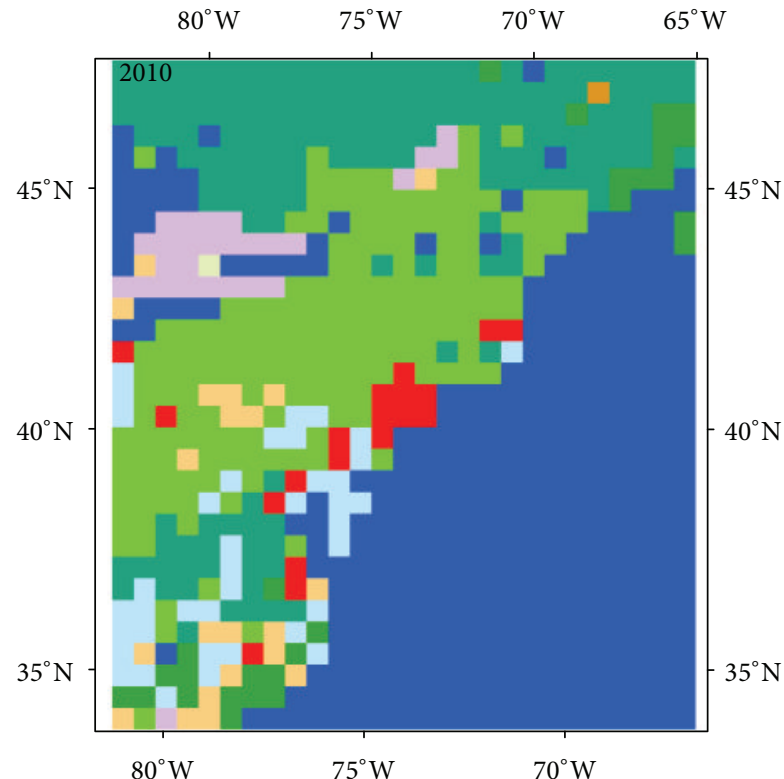

(b)

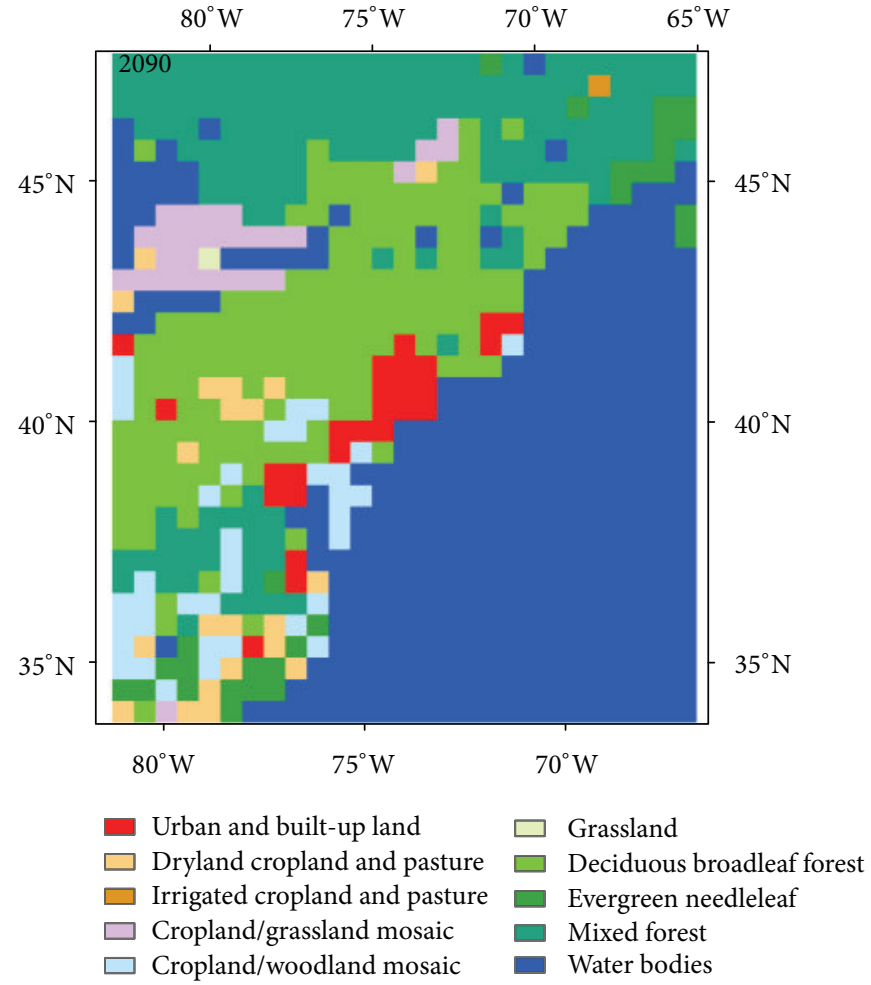

(d)

FIgURE 2: Baseline underlying surface data (1993) and predicted underlying surface data (2010, 2040, and 2090) used in this study.

There will be some nonurban pixels experiencing average annual temperature decrease due to future urban expansions while the average annual temperature of most nonurban areas will be steady. The significant average annual temperature decrease will mainly happen in the south of the Northeast megalopolis with mixed forest (Figure 3). The statistics shows that this average annual temperature decrease will range from $0.40^{\circ} \mathrm{C}$ to $1.20^{\circ} \mathrm{C}$. And along with the urban expansion, the cooling effect in this area will be more and more notable. This maybe because the strengthened UHI due to urban expansion enhances the rising flow of urban area and consequently results in the inflow of cold wet air stream from the sea. 


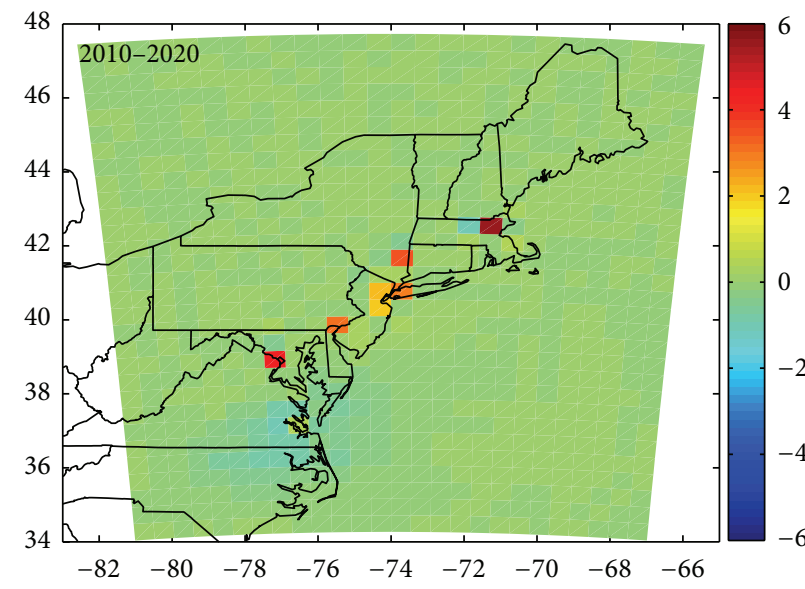

(a)

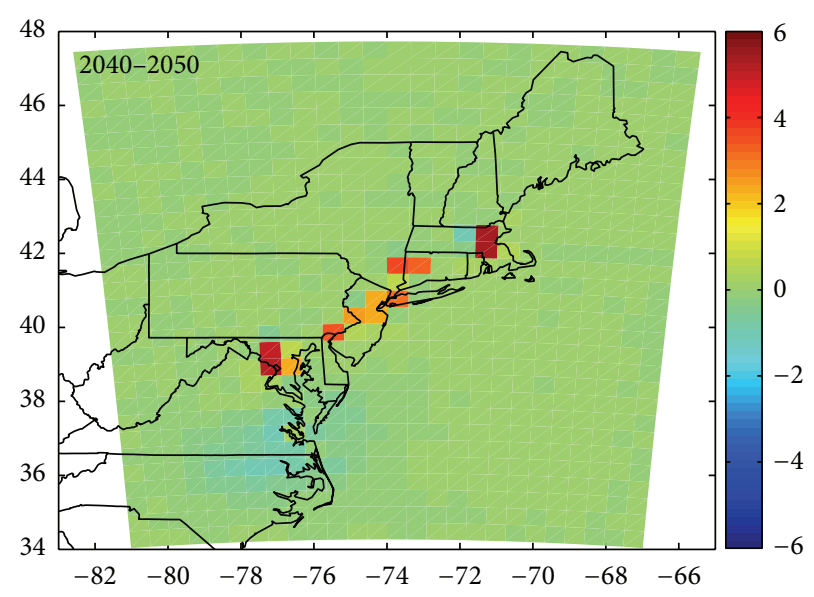

(b)

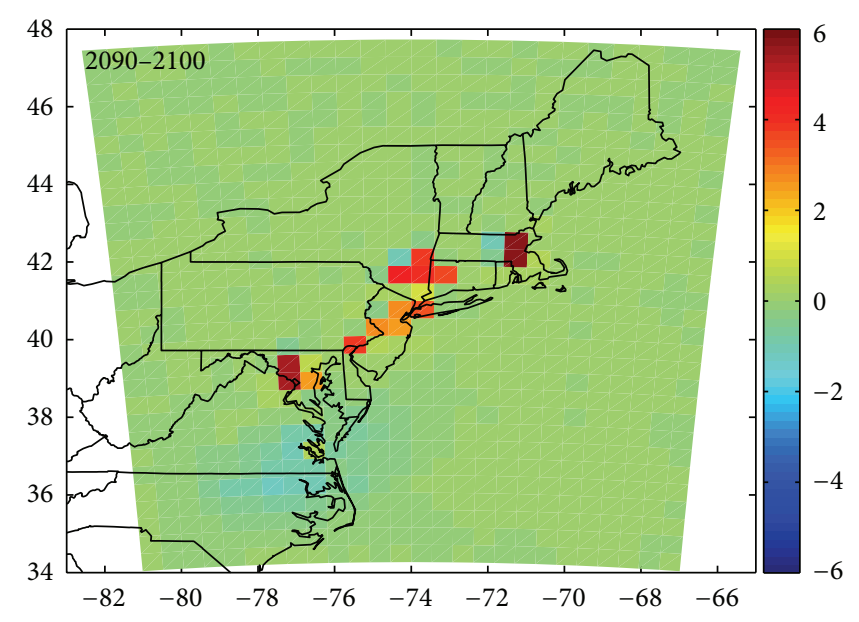

(c)

FIGURE 3: Effects of future urban expansion on average annual temperature in the Northeast megalopolis, USA (unit: ${ }^{\circ} \mathrm{C}$ ).

3.2. Average Annual Precipitation Effects. The effects of future urban expansion on average annual precipitation will mainly be negative. The spatial pattern of average annual precipitation change will be approximately the opposite to that of average annual temperature change (Figure 4). For some new urban area and most of the pixels around urban areas, the average annual precipitation will decrease by $10 \mathrm{~mm}$ to $50 \mathrm{~mm}$. And the average annual precipitation will be reduced by more than $100 \mathrm{~mm}$ for some pixels in the south region of the Northeast megalopolis. This reduction may be caused by changes in surface hydrology that extend beyond the UHI effect. There were a lot of researches that argue about urban expansion resulting in an increase of urban precipitation [21, 25, 35-37]. But our simulation showed that the future urban expansion in Northeast megalopolis with mega cities on precipitation has different rules. This simulation result is consistent with the findings of Guo et al., and Zhang et al., though their study area of Beijing is much smaller than ours on scale $[6,24]$. The urban expansion will produce less evaporation, higher surface temperatures, and larger sensible heat fluxes. This leads to less water vapor and hence less convective available potential energy (CAPE). Combination of these factors induced by urban expansion contributes to regional precipitation reduction in general. Concretely, due to urban expansion in the Northeast megalopolis, the average annual precipitation of the simulation area will decrease by $5.75 \mathrm{~mm}, 7.10 \mathrm{~mm}$, and $8.35 \mathrm{~mm}$ in the periods of 2010-2020, 2040-2050, and 2090-2100, respectively.

\subsection{Average Monthly Temperature Effects. Figure 5 depicts} the monthly variation of average temperature change driven by future urban expansion. The urban expansion in the Northeast megalopolis will result in an average monthly temperature increase in original urban area (urban area in 1993) in April, May, June, July, and August and opposite in other months in the period of 2010-2020 (Figure 5(a)). The cooling effect in winter may be because of the local circulation change caused by surface energy budgets change. And along with urban expansion in the periods of 2040-2050, and 2090-2100, the cooling effect will be weakened, which can be referred to the enhancement of UHI effect. The urban expansion during these two periods will result in an average monthly temperature increase from February to October and opposite in the other three months. The average monthly 


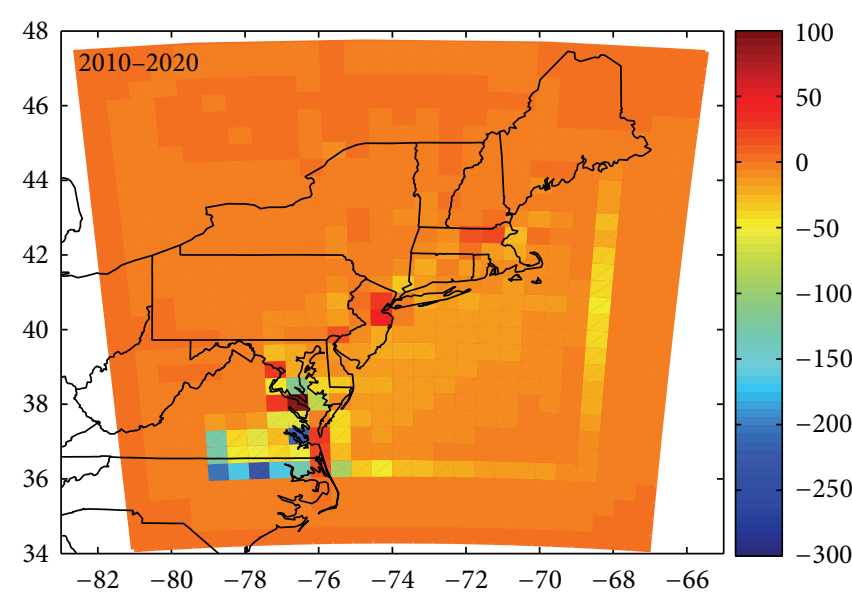

(a)

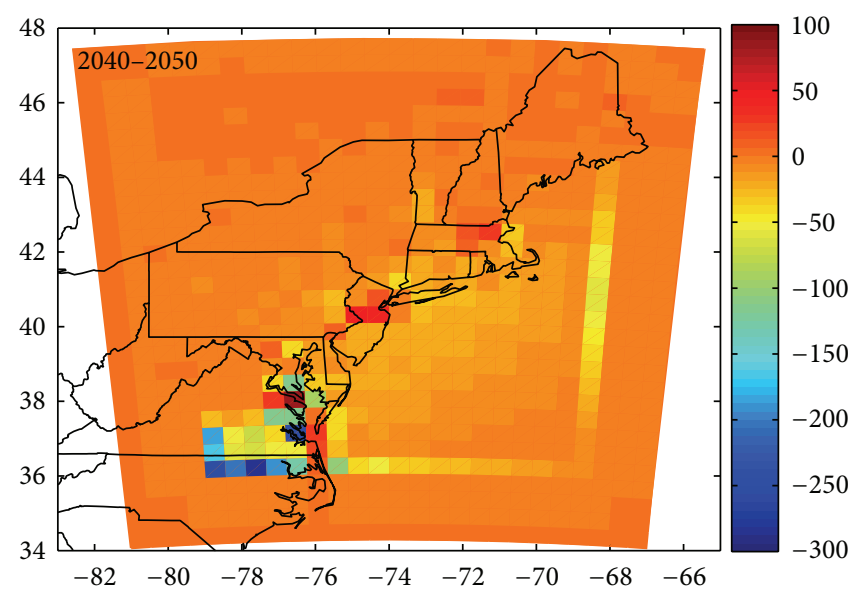

(b)

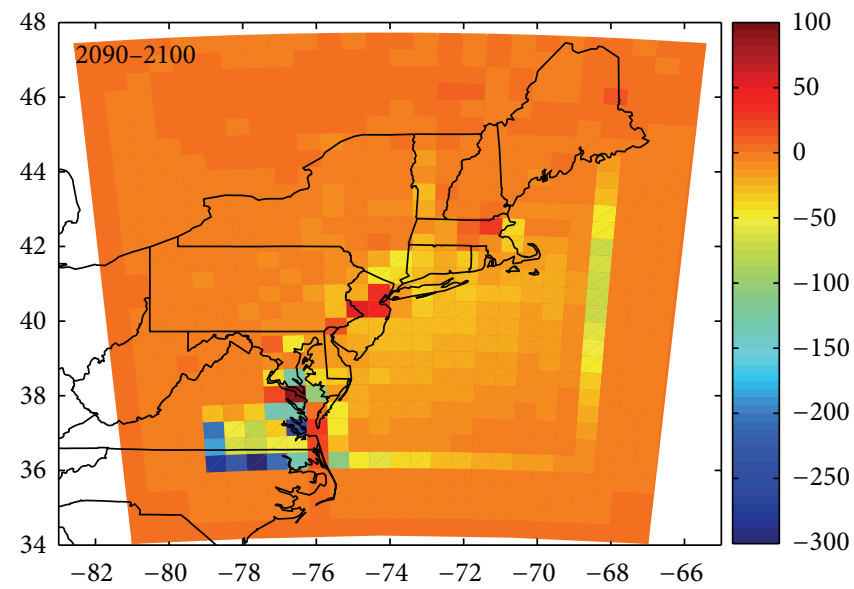

(c)

FIGURE 4: Effects of future urban expansion on average annual precipitation in the Northeast megalopolis, USA (unit: mm).

temperature increase in June and July in original urban area will exceed $0.4^{\circ} \mathrm{C}$ in the period of $2090-2100$ due to urban expansion. And on the whole, the future urban expansion will lead to an average monthly temperature increase in original urban area.

The warming effect of future urban expansion in new urban area will be more significant than that in original urban area and more serious in summer than in winter (Figure 5(b)). Particularly in June, the urban expansion will lead to an average monthly temperature increase by $1.92^{\circ} \mathrm{C}$, $3.16^{\circ} \mathrm{C}$, and $3.59^{\circ} \mathrm{C}$ in new urban area in the periods of 2010 2020, 2040-2050, and 2090-2100, respectively. There will be also a cooling effect in new urban area in November, December, and January during the period of 2010-2020. But it is tiny compared with the notable average monthly temperature increase in the other months. The differences of average monthly temperature change among the three simulation periods indicate that the UHI effect in new urban area will enhance along with urban expansion.

And in nonurban area, the effects of future urban expansion on average monthly temperature will also vary from month to month. We counted the number of pixels with average monthly temperature changes exceeding $\pm 0.5^{\circ} \mathrm{C}$ (Figure 6(a)). This number indicates the area that is severely influenced by future urban expansion on average monthly temperature. The results show that the influence area of future urban expansion on average monthly temperature will be larger in the period from July to January. And at least 20 pixels, which means an area of more than $5.00 \times 10^{4} \mathrm{~km}^{2}$, will be affected by future urban expansion and experience average monthly temperature changes exceeding $\pm 0.5^{\circ} \mathrm{C}$ in these months. Particularly in the period of 2090 to 2100 , the urban expansion will lead to an average monthly temperature changes of more than $\pm 0.5^{\circ} \mathrm{C}$ in a vast area of $1.10 \times 10^{5} \mathrm{~km}^{2}$. And the increase of pixels with average monthly temperature changes exceeding $\pm 0.5^{\circ} \mathrm{C}$ along with time indicates that the influence area extends along with future urban expansion. In sum, the larger area urban expands, the more notable the effects of future urban expansion on average monthly temperature will be.

3.4. Average Monthly Precipitation Effects. There will be negative effects of future urban expansion on average monthly precipitation in original urban area though slight. Similar 


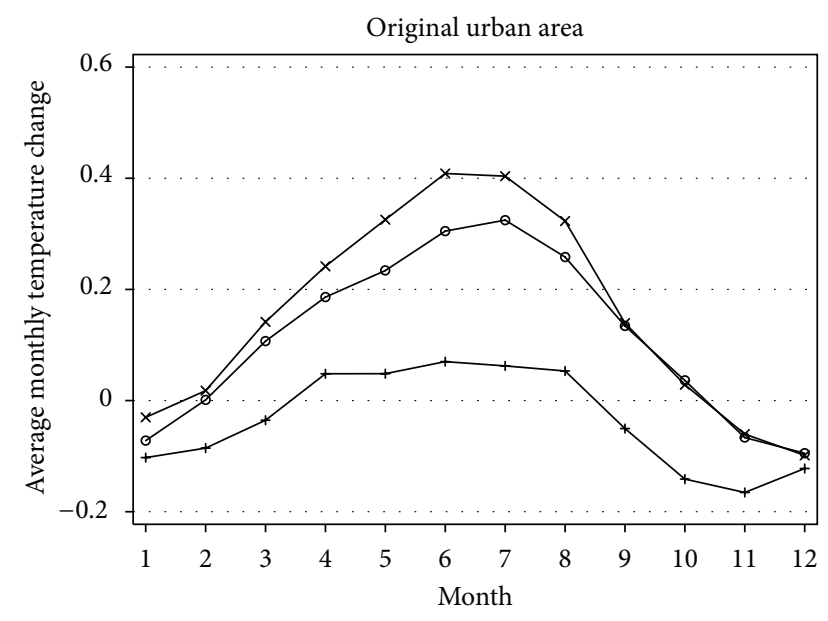

(a)

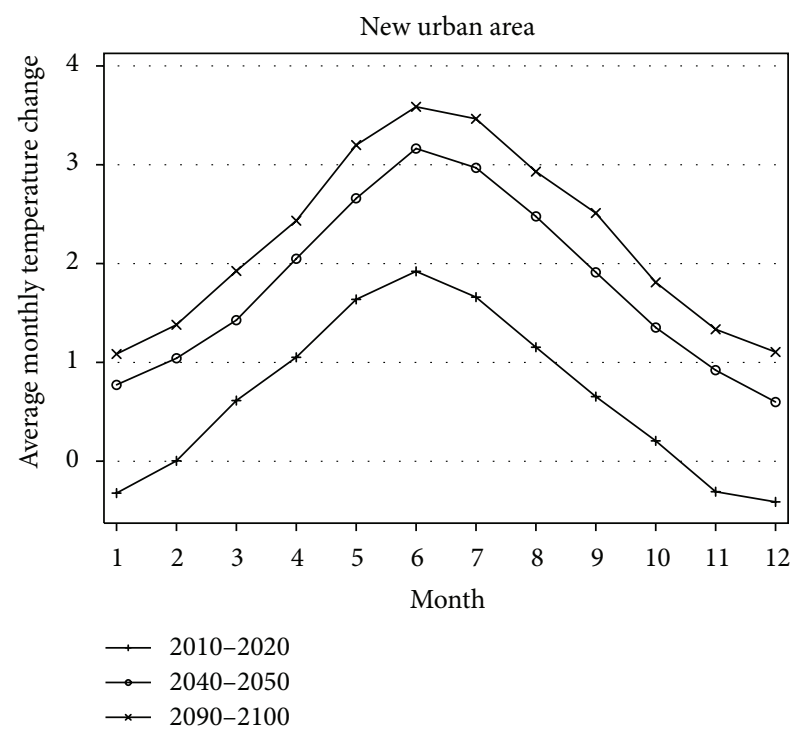

(b)

FIGURE 5: Effects of future urban expansion on average monthly temperature in urban area in the Northeast megalopolis, USA (unit: $\left.{ }^{\circ} \mathrm{C}\right)$.

to average monthly temperature, the change of average monthly precipitation in original urban area caused by future urban expansion will be more significant in summer than in winter (Figure 7(a)). The urban expansion-induced average monthly precipitation decrease in original urban area will reach its maximum of $0.49 \mathrm{~mm}, 0.69 \mathrm{~mm}$, and $0.71 \mathrm{~mm}$ in July in the periods of 2010-2020, 2040-2050, and 20902100 , respectively. And it will fall to its minimum of $0.04 \mathrm{~mm}$ in December in the periods of 2010-2020, and $0.02 \mathrm{~mm}$ and $0.01 \mathrm{~mm}$ in January in the periods of 2040-2050, and 2090-2100, respectively. The effects of future urban expansion on average monthly precipitation will continuously increase from January to July, and then turn to fall until December. This change of average monthly precipitation in original urban area may be because of the local circulation change caused by surface energy budgets change and can be easily

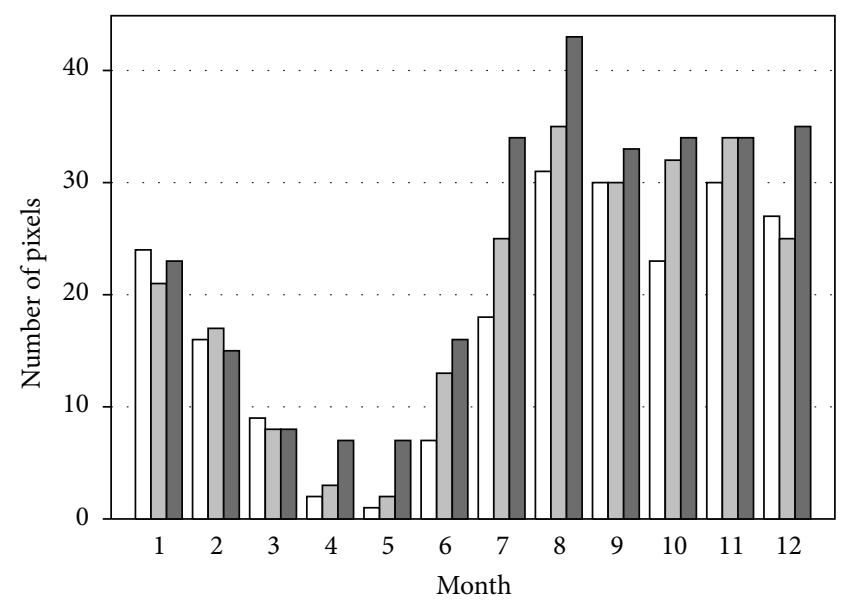

(a)

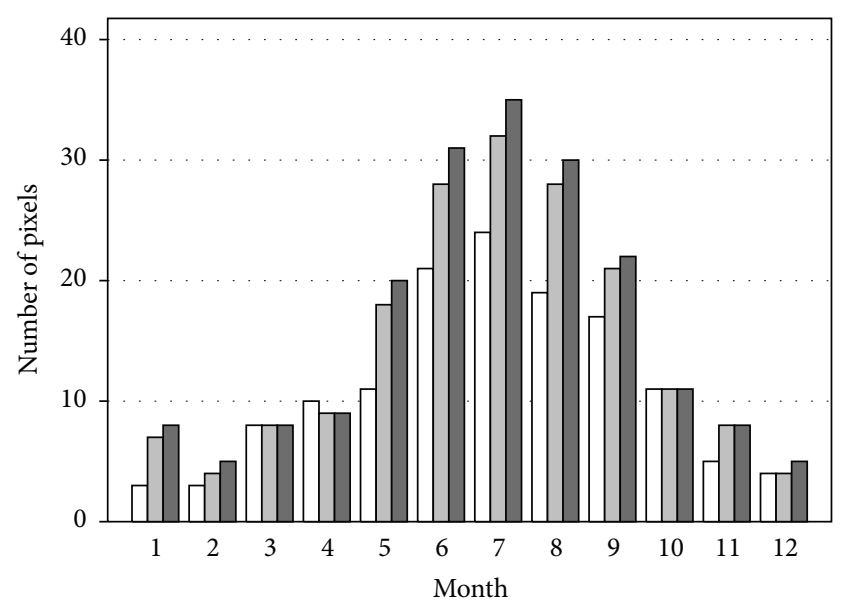

$2010-2020$
$2040-2050$
$2090-2100$

(b)

Figure 6: Effects of future urban expansion on average monthly temperature and precipitation in nonurban area in the Northeast megalopolis, USA. (a) Number of pixels with average monthly temperature change exceeding $\pm 0.5^{\circ} \mathrm{C}$; (b) number of pixels with average monthly precipitation change exceeding $\pm 1 \mathrm{~mm}$.

found to be more and more serious along with future urban expansion.

The drought effect of future urban expansion in new urban area will be more significant than that in original urban area (Figure $7(b)$ ). The most severe reduction of average monthly precipitation will occur in October with decreases of $11.82 \mathrm{~mm}, 9.23 \mathrm{~mm}$, and $8.14 \mathrm{~mm}$ in the periods of 2010 2020, 2040-2050, and 2090-2100, respectively. After October, the drought effect of future urban expansion in new urban area will begin to weaken and gradually fall to its minimum (between $2 \mathrm{~mm}$ and $3 \mathrm{~mm}$ ) in May. And then, it will turn over rapidly and become more and more severe. Contrary to the effects of future urban expansion on average monthly precipitation in original urban area, larger urban area will result in slighter drought effect in new urban area. This can 


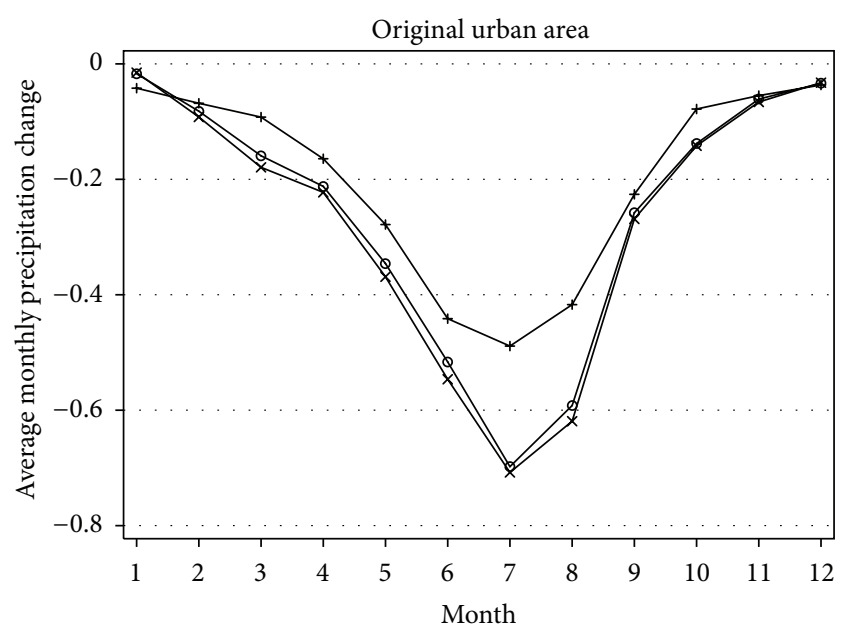

(a)

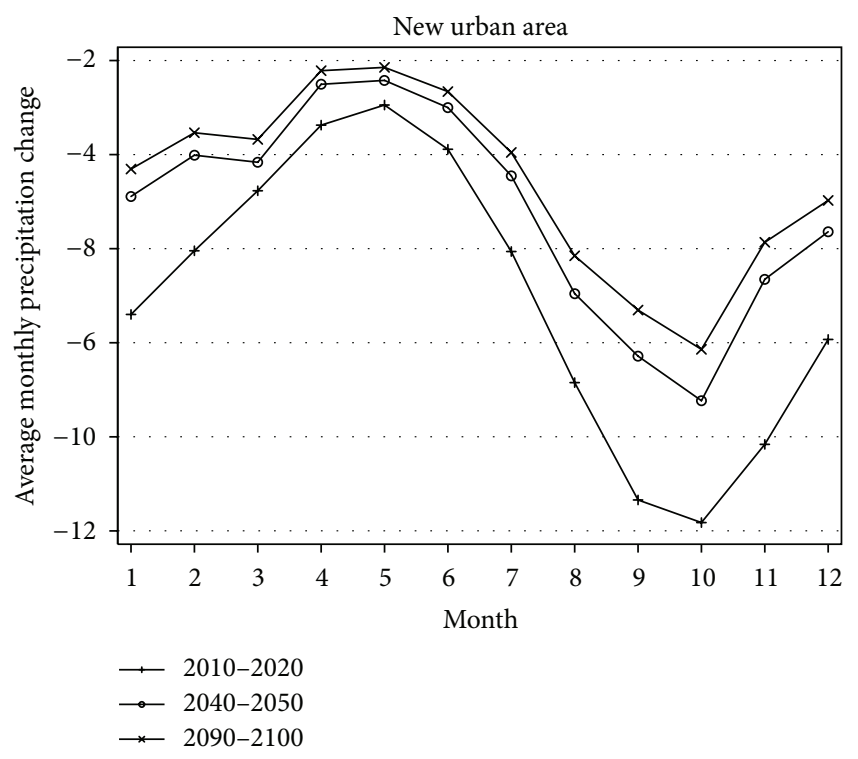

(b)

FIGURE 7: Effects of future urban expansion on average monthly precipitation in urban area in the Northeast megalopolis, USA (unit: $\mathrm{mm})$.

be deduced from the phenomenon that the average monthly precipitation decreases in the periods of 2040-2050, and 2090-2100 will be smaller than that in the periods of 20102020. It may be because that the enhancement of UHI effect in the Northeast megalopolis will arouse the inflow of humid air from the Atlantic.

To investigate the effects of future urban expansion on average monthly precipitation in nonurban area, we counted the number of pixels with average monthly precipitation changes exceeding $\pm 1 \mathrm{~mm}$ (Figure 6(b)). This number indicates the influence area of future urban expansion on average monthly precipitation to some extent. The results show that the influence area of future urban expansion on average monthly precipitation will be larger in summer than in winter. A rapider urban expands will lead to more distant effects.
For instance, the number of pixels with average monthly precipitation changes more than $\pm 1 \mathrm{~mm}$ in July will be 35 (covering an area of $8.75 \times 10^{4} \mathrm{~km}^{2}$ ) in the period of 2090 2100 , and 32 (covering an area of $8.00 \times 10^{4} \mathrm{~km}^{2}$ ) and 24 (covering an area of $6.00 \times 10^{4} \mathrm{~km}^{2}$ ) in the periods of $2040-$ 2050 and 2090-2100, respectively. It implies the area with average monthly precipitation changes more than $\pm 1 \mathrm{~mm}$ caused by future urban expansion will increase persistently along with urban expansion.

\section{Conclusions}

A simulation-based research on the intension and scope of influences of future urban expansion on regional climate on different time scales in developed megalopolis was implemented. The average annual and monthly temperature and precipitation change caused by urban expansion from 1993 to 2100 were presented taking the Northeast megalopolis, USA as a case study area. Some conclusions were drawn as follows.

(i) It can be seen from the above analysis that the future urban expansion will result in an average annual temperature increase ranging from $2^{\circ} \mathrm{C}$ to $5^{\circ} \mathrm{C}$ in new urban area and an average annual temperature decrease ranging from $0.40^{\circ} \mathrm{C}$ to $1.20^{\circ} \mathrm{C}$ in the south of the Northeast megalopolis. The average annual precipitation of our simulation area will be reduced by $5.75 \mathrm{~mm}, 7.10 \mathrm{~mm}$, and $8.35 \mathrm{~mm}$ due to urban expansion in the periods of 2010-2020, 2040-2050, and 2090-2100, respectively. This reduction is especially severe in the south region of the Northeast megalopolis.

(ii) The effects of future urban expansion on average monthly temperature will vary from month to month and become more and more severe along with urban expansion not only in original and new urban area but also in nonurban area. The warming effect of future urban expansion in original and new urban area will be more serious in summer than in winter. And there will be a cooling effect in winter in original urban area.

(iii) The effects of future urban expansion on average monthly precipitation will be severe in new urban area but in original urban area. The drought effect in new urban area will weaken along with urban expansion. The influence area of future urban expansion on average monthly precipitation in nonurban area will be larger in summer than in winter and will increase along with urban expansion.

(iv) The influence rules of urban expansion on climate revealed at the scale of megalopolis differ from those in a single city. A large-scale study on the impacts of urban expansion on climate helps to understand the integrated effect of combination and interaction of multiple cities and their surrounding areas. And this integrated effect may crucially determine the climate pattern. 


\section{Acknowledgments}

This research was supported by the National Key Programme for Developing Basic Science in China (no. 2010CB950904), the Key Project funded by the Chinese Academy of Sciences (no. KZZD-EW-08), and the External Cooperation Program of the Chinese Academy of Sciences (no. GJHZ1312).

\section{References}

[1] Q. Weng, "Fractal analysis of satellite-detected urban heat island effect," Photogrammetric Engineering and Remote Sensing, vol. 69, no. 5, pp. 555-566, 2003.

[2] J. B. Basara, H. G. Basara, B. G. Illston, and K. C. Crawford, "The impact of the urban heat island during an intense heat wave in Oklahoma City," Advances in Meteorology, vol. 2010, Article ID 230365, 10 pages, 2010.

[3] J. A. Voogt and T. R. Oke, "Thermal remote sensing of urban climates," Remote Sensing of Environment, vol. 86, no. 3, pp. 370384, 2003.

[4] Q. H. Weng, D. S. Lu, and J. Schubring, "Estimation of land surface temperature-vegetation abundance relationship for urban heat island studies," Remote Sensing of Environment, vol. 89, no. 4, pp. 467-483, 2004.

[5] M. Stathopoulou, A. Synnefa, C. Cartalis, M. Santamouris, T. Karlessi, and H. Akbari, "A surface heat island study of Athens using high-resolution satellite imagery and measurements of the optical and thermal properties of commonly used building and paving materials," International Journal of Sustainable Energy, vol. 28, no. 1-3, pp. 59-76, 2009.

[6] C. L. Zhang, F. Chen, S. G. Miao, Q. C. Li, X. A. Xia, and C. Y. Xuan, "Impacts of urban expansion and future green planting on summer precipitation in the Beijing metropolitan area," Journal of Geophysical Research D, vol. 114, no. 2, Article ID D02116, 2009.

[7] G. L. Makokha and C. A. Shisanya, "Temperature cooling and warming rates in three different built environments within Nairobi City, Kenya," Advances in Meteorology, vol. 2010, Article ID 686214, 5 pages, 2010.

[8] R. Bornstein and Q. Lin, "Urban heat islands and summertime convective thunderstorms in Atlanta: three case studies," Atmospheric Environment, vol. 34, no. 3, pp. 507-516, 2000.

[9] R. A. Pielke Sr., G. Marland, R. A. Betts et al., "The influence of land-use change and landscape dynamics on the climate system: relevance to climate-change policy beyond the radiative effect of greenhouse gases," Philosophical Transactions of the Royal Society A, vol. 360, no. 1797, pp. 1705-1719, 2002.

[10] D. Niyogi, T. Holt, S. Zhong, P. C. Pyle, and J. Basara, "Urban and land surface effects on the 30 July 2003 mesoscale convective system event observed in the Southern Great Plains," Journal of Geophysical Research D, vol. 111, no. 19, Article ID D19107, 2006.

[11] M. Lei, D. Niyogi, C. Kishtawal et al., "Effect of explicit urban land surface representation on the simulation of the 26 July 2005 heavy rain event over Mumbai, India," Atmospheric Chemistry and Physics, vol. 8, no. 20, pp. 5975-5995, 2008.

[12] T. R. Oke and G. B. Maxwell, "Urban heat island dynamics in Montreal and Vancouver," Atmospheric Environment, vol. 9, no. 2, pp. 191-200, 1975.

[13] D. E. Parker, "Large-scale warming is not urban," Nature, vol. 432, no. 7015, p. 290, 2004.
[14] R. Emmanuel and E. Krüger, "Urban heat island and its impact on climate change resilience in a shrinking city: the case of Glasgow, UK," Building and Environment, vol. 53, pp. 137-149, 2012.

[15] R. D. Bornstein, "Observations of the urban heat island effect in New York city," Journal of Applied Meteorology, vol. 7, no. 4, pp. 575-582, 1968.

[16] E. Kalnay and M. Cai, "Impact of urbanization and land-use change on climate," Nature, vol. 423, no. 6939, pp. 528-531, 2003.

[17] C. Rosenzweig, W. D. Solecki, L. Parshall, M. Chopping, G. Pope, and R. Goldberg, "Characterizing the urban heat island in current and future climates in New Jersey," Global Environmental Change B, vol. 6, no. 1, pp. 51-62, 2005.

[18] F. Yuan and M. E. Bauer, "Comparison of impervious surface area and normalized difference vegetation index as indicators of surface urban heat island effects in Landsat imagery," Remote Sensing of Environment, vol. 106, no. 3, pp. 375-386, 2007.

[19] S. R. Gaffin, C. Rosenzweig, R. Khanbilvardi et al., "Variations in New York city's urban heat island strength over time and space," Theoretical and Applied Climatology, vol. 94, no. 1-2, pp. 1-11, 2008.

[20] M. L. Imhoff, P. Zhang, R. E. Wolfe, and L. Bounoua, "Remote sensing of the urban heat island effect across biomes in the continental USA," Remote Sensing of Environment, vol. 114, no. 3, pp. 504-513, 2010.

[21] L. Kleerekoper, M. van Esch, and T. B. Salcedo, "How to make a city climate-proof, addressing the urban heat island effect," Resources, Conservation and Recycling, vol. 64, pp. 30-38, 2012.

[22] L. Tian, J. Q. Chen, and S. X. Yu, "How has Shenzhen been heated up during the rapid urban build-up process?" Landscape and Urban Planning, vol. 115, pp. 18-29, 2013.

[23] J. Marshall Shepherd, M. Carter, M. Manyin, D. Messen, and S. Burian, "The impact of urbanization on current and future coastal precipitation: a case study for houston," Environment and Planning B, vol. 37, no. 2, pp. 284-304, 2010.

[24] X. L. Guo, D. H. Fu, and J. Wang, "Mesoscale convective precipitation system modified by urbanization in Beijing city," Atmospheric Research, vol. 82, no. 1-2, pp. 112-126, 2006.

[25] C. Y. Lin, W. C. Chen, S. C. Liu, Y. A. Liou, G. R. Liu, and T. H. Lin, "Numerical study of the impact of urbanization on the precipitation over Taiwan," Atmospheric Environment, vol. 42, no. 13, pp. 2934-2947, 2008.

[26] K. Trusilova, M. Jung, G. Churkina, U. Karsten, M. Heimann, and M. Claussen, "Urbanization impacts on the climate in Europe: numerical experiments by the PSU-NCAR mesoscale model (MM5)," Journal of Applied Meteorology and Climatology, vol. 47, no. 5, pp. 1442-1455, 2008.

[27] M. Z. Jacobson and J. E. T. Hoeve, "Effects of urban surfaces and white roofs on global and regional climate," Journal of Climate, vol. 25, no. 3, pp. 1028-1044, 2012.

[28] Y. F. Sang, Z. G. Wang, Z. L. Li, C. M. Liu, and X. J. Liu, "Investigation into the daily precipitation variability in the Yangtze River Delta, China," Hydrological Processes, vol. 27, no. 2, pp. 175-185, 2013.

[29] J. Gottmann, Megalopolis: The Urbanized Northeastern Seaboard of the United States, MIT Press, Cambridge, Mass, USA, 1961.

[30] G. A. Grell, J. Dudhia, and D. R. Stauffer, "A description of the fifth-generation PennState/NCAR mesoscale model (MM5)," NCAR Technical Note, NCAR, Boulder, Colo, USA, 1995.

[31] J. Fujino, R. Nair, M. Kainuma, T. Masui, and Y. Matsuoka, "Multi-gas mitigation analysis on stabilization scenarios using aim global model," Energy Journal, vol. 27, pp. 343-354, 2006. 
[32] Y. Hijioka, Y. Matsuoka, H. Nishimoto, T. Masui, and M. Kainuma, "Global GHG emission scenarios under GHG concentration stabilization targets," Journal of Global Environment Engineering, vol. 13, pp. 97-108, 2008.

[33] G. A. Meehl, L. Goddard, J. Murphy et al., "Decadal prediction: can it be skillful?" Bulletin of the American Meteorological Society, vol. 90, no. 10, pp. 1467-1485, 2009.

[34] K. E. Taylor, R. J. Stouffer, and G. A. Meehl, "An overview of CMIP5 and the experiment design," Bulletin of the American Meteorological Society, vol. 93, no. 4, pp. 485-498, 2012.

[35] K. J. Craig, MM5 simulations of urban induced convective precipitation over Atlanta, GA [Thesis], Faculty of the Department of Meteorology San Jose State University, 2002.

[36] C. M. Rozoff, W. R. Cotton, and J. O. Adegoke, "Simulation of St. Louis, Missouri, land use impacts on thunderstorms," Journal of Applied Meteorology, vol. 42, pp. 716-738, 2003.

[37] M. A. F. S. Dias, J. Dias, L. M. V. Carvalho, E. D. Freitas, and P. L. S. Dias, "Changes in extreme daily rainfall for São Paulo, Brazil," Climatic Change, vol. 116, no. 3-4, pp. 705-722, 2013. 

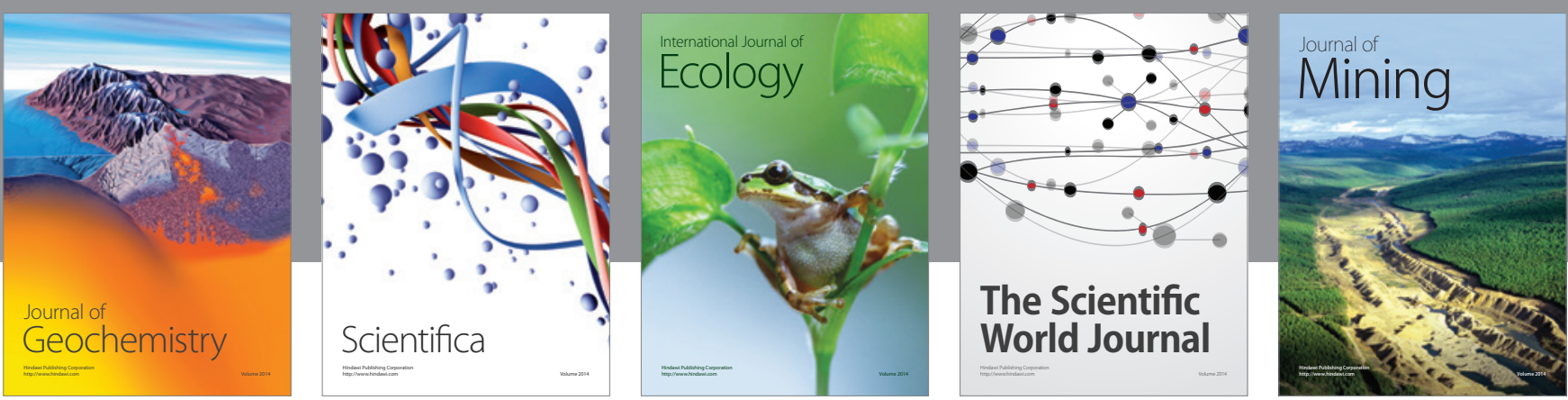

The Scientific World Journal
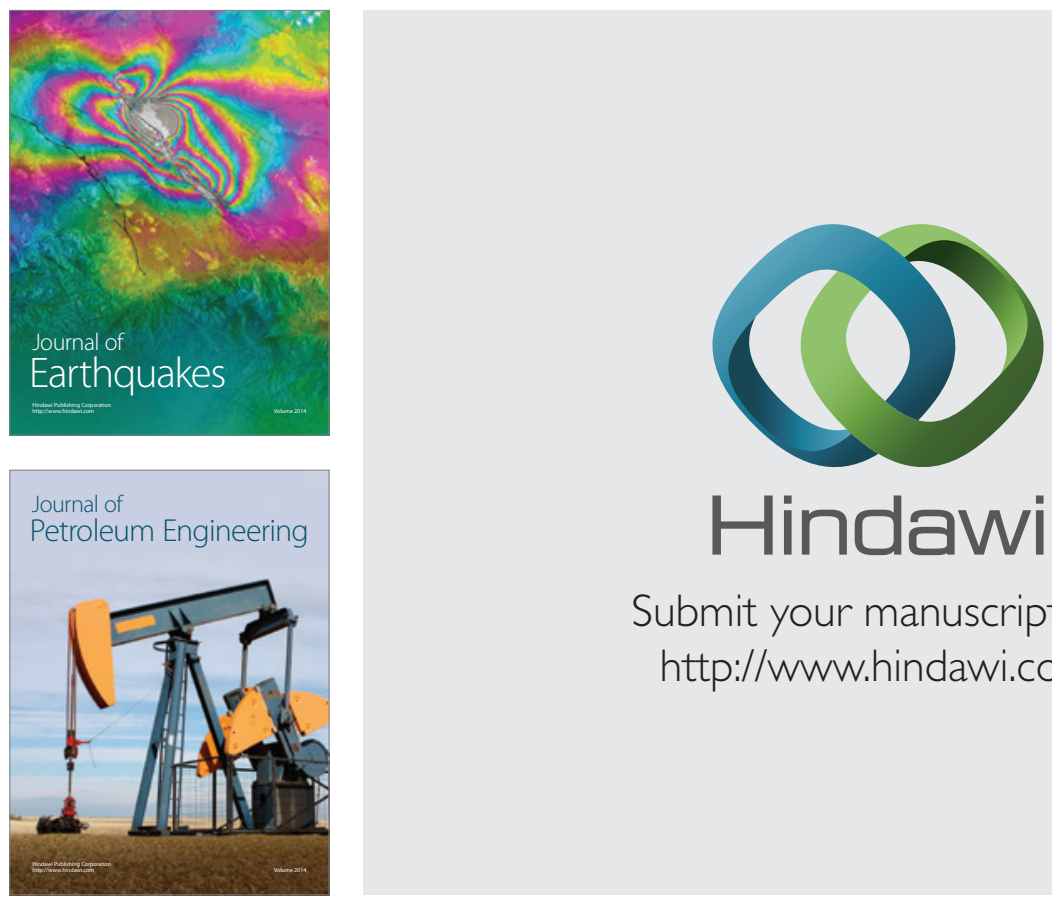

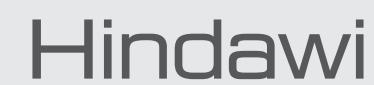

Submit your manuscripts at

http://www.hindawi.com
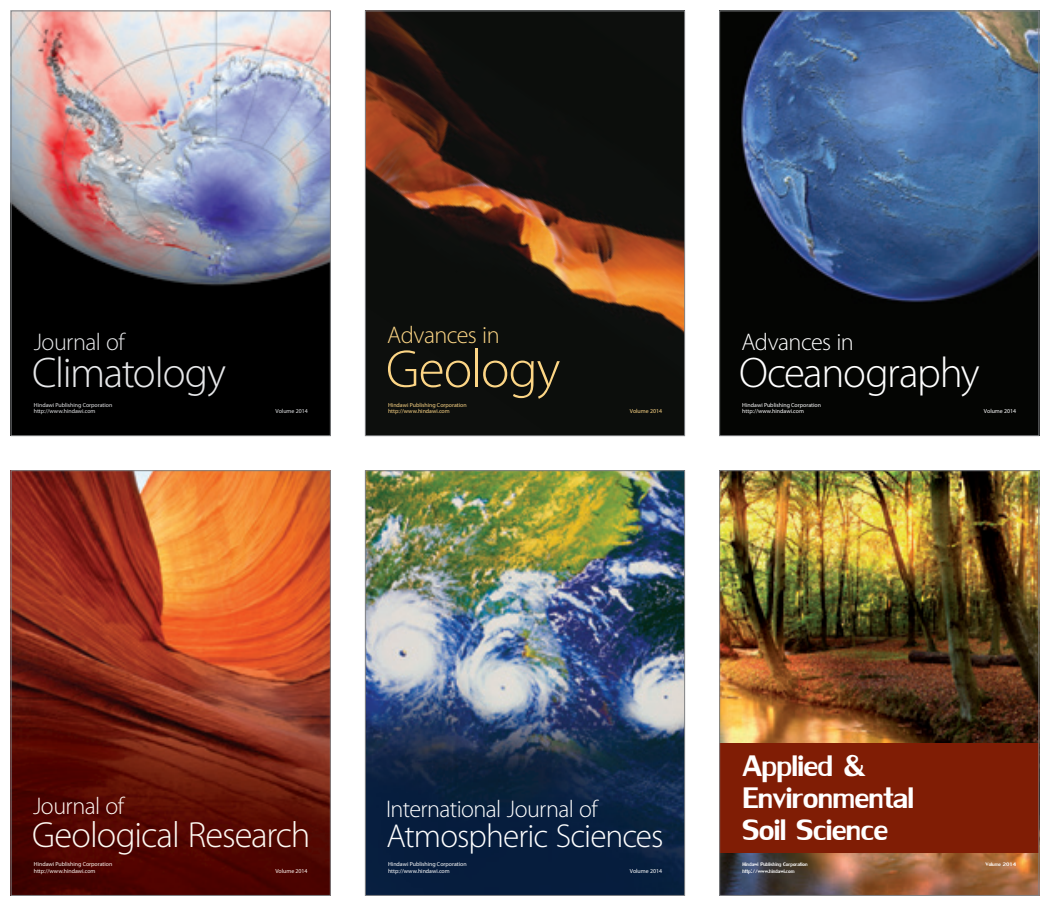
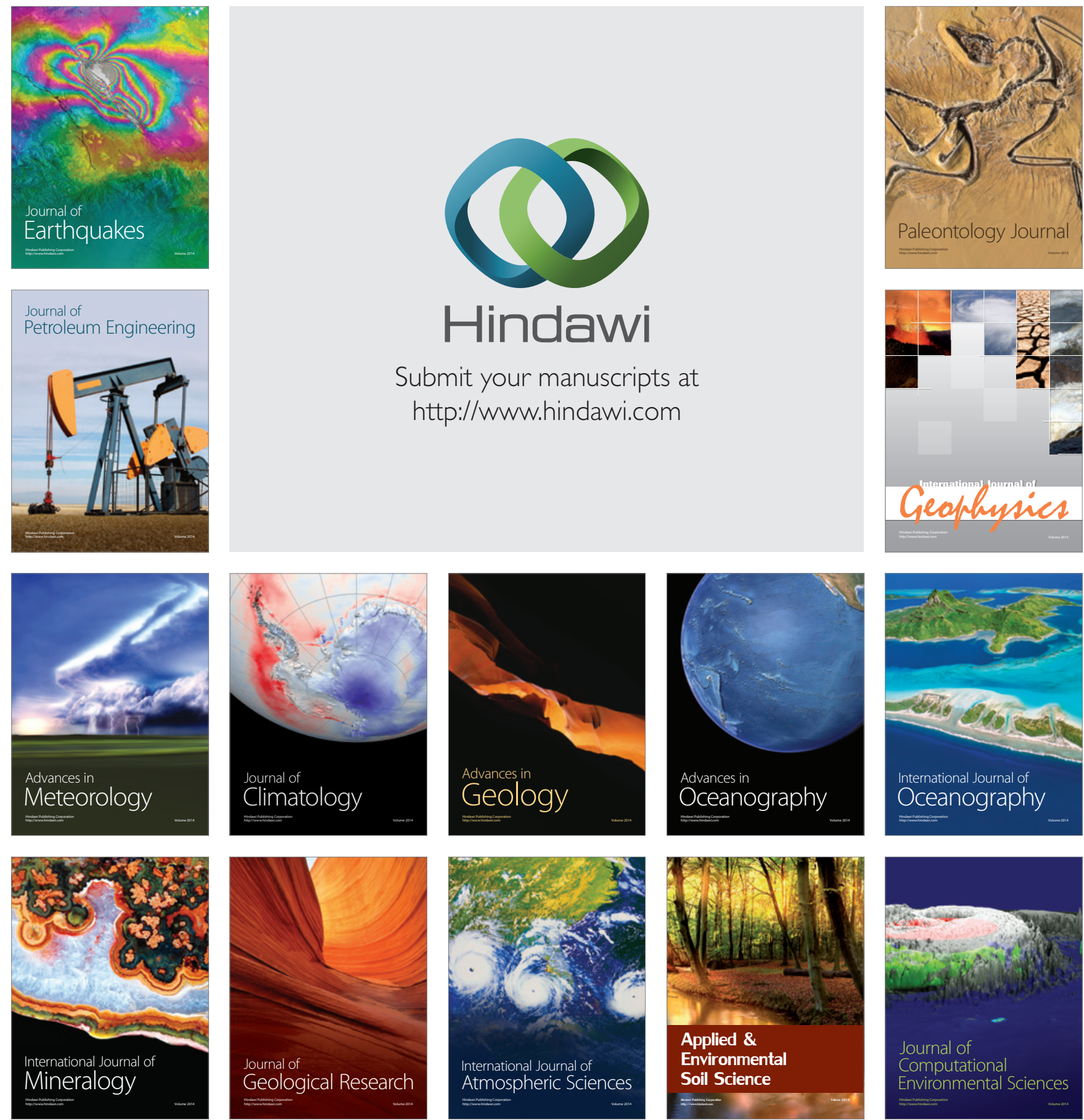